\title{
Signet Ring Cell Carcinoma of Ampulla of Vater: Report of a Rare Malignancy and Literature Review
}

\author{
Ihsane Souaf, Kawtar Znati, Sanae Chahbouni, Imane Hafid, Hassania Ameurtesse, \\ Nawale Hammas, Leila Chbani, Hinde El Fatemi, Tawfik Harmouch, Afaf Amarti \\ Department of Pathology, Hassan II University Hospital of Fez, Hassan, Morocco \\ Email: souafihsane@gmail.com
}

Received 15 February 2014; revised 4 March 2014; accepted 15 March 2014

Copyright (C) 2014 by authors and Scientific Research Publishing Inc.

This work is licensed under the Creative Commons Attribution International License (CC BY). http://creativecommons.org/licenses/by/4.0/

\begin{abstract}
Introduction: Signet ring cell carcinoma is a rare tumor that generally originates in the gastrointestinal tract. Signet-ring cell carcinoma of the ampulla of Vater is extremely uncommon and a very rare clinical entity, which is infrequently reported in medical literature and only 31 cases have been mentioned. Most tumors affecting Vater's Ampulla are adenocarcinomas and other histological variants are less frequent. It mainly occurs in elderly patients. Case Presentation: We report a case of signet ring cell carcinoma of Vater's Ampulla. The tumour had infiltrated the duodenal, but local lymph nodes were clear (T3NOMO). Duodenopancreatectomy with pylorus preservation is the treatment of choice. Conclusions: Etiology and survival are not well-defined in the literature due to the extreme rarity of this disease.
\end{abstract}

Keywords

Ampulla of Vater; Carcinoma; Signet Ring Cell; Pancreas

\section{Introduction}

Signet ring cell carcinoma (SRCC) is more commonly found in the stomach than at other sites in the digestive system. Malignant tumors of Vater's Ampulla are usually well-differentiated adenocarcinomas, and the signet ring cell variant of ampullary adenocarcinoma is rare [1]. 32 previous cases of SRCC ampullary have been mentioned in medical literature [2]. The World Health Organization (WHO) defines it as a special type or a variant of gastrointestinal adenocarcinoma. SRCC may exist alone or coexist with any other types of malignant gastrointestinal tumors [3]. We present an elderly patient with SRCC of Vater's Ampulla without nodal metastasis. 


\section{Case Presentation}

We report the case of a 57-year-old man, admitted with jaundice, abdominal pain four months ago and $10 \mathrm{~kg}$ weight loss. Abdominal ultrasound showed dilatation of the common bile duct and the intrahepatic bile ducts. No locoregional lymph nodes were observed. Abdominal computed tomography (Figure 1) and Bili-IRM showed a tumor in the ampulla of Vater with invasion of D3 and a dilatation of the extra hepatic bile duct whithout loco regional lymph nodes. Duodenoscopy confirmed the presence of a Vater's ampulla tumor and histology of the biopsy revealed a signet ring cell carcinoma. A cephalic duodenopancreatectomy and extended lymphadenectomy were performed.

The final pathological examination confirmed an SRCC of the ampulla of Vater (Figures 2 and 3) and the duodenum were infiltrated with carcinoma. No distal or nodal metastases were identified and no evidence of lymphatic and vascular invasion. The ampullary cancer was classified as T3N0M0 and six cycles of adjuvant chemotherapy based on CISPLATIN + GEMCITABINE were performed with good clinical tolerance. There was no evidence of local tumor recurrence and metastatic on postoperative computed tomography scans during 10 months.

\section{Discussion}

Adenocarcinoma of Vater's ampulla is a rare clinical entity, occurring in less than six cases per million people annually [4]. It accounts for $0.2 \%$ of all gastrointestinal and $6 \%$ of periampullary malignancies [4] [5].

SRCC can arise in many organs, but it usually occurs in the gastrointestinal tract, especially in the stomach. It has been reported that $90 \%$ of SRCC occurs in the stomach, with the rest arising in several other organs, including the breast, gallbladder, pancreas, urinary bladder and colon [6].

SRCC of Vater's ampulla represents a variant of adenocarcinoma, characterised by the presence of greater than 50\% signetring cells with intra-cytoplasmic mucin, and typically eccentrically-located crescent-shaped

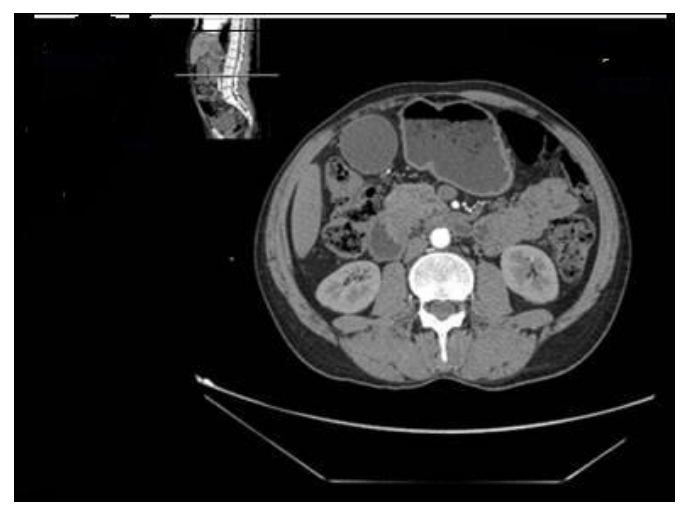

Figure 1. Scan of the abdomen cut showed a process of Vater's ampulla.

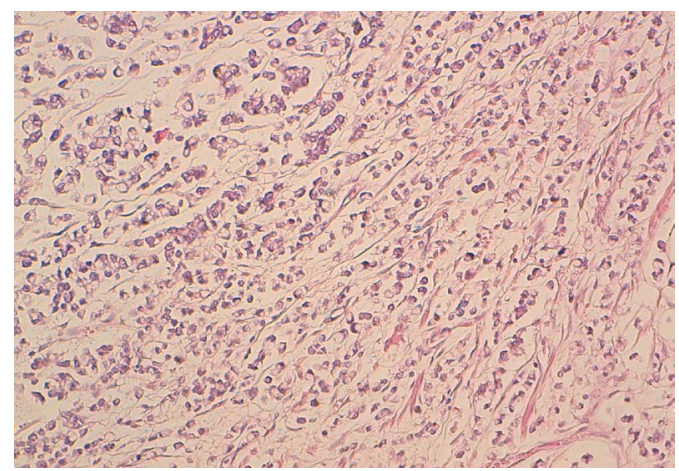

Figure 2. HES $\times 20$ : The tumor was only formed by signet ring cell carcinoma. 


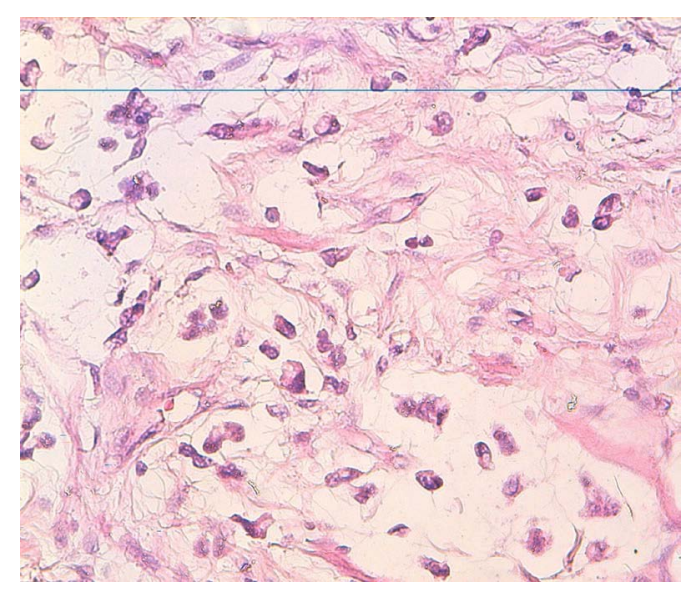

Figure 3. HES $\times 40$ : Signet-ring cell carcinoma composed of single, non cohesive, round and vacuolated cells containing intra-cytoplasmic mucin.

nuclei [4]. It is extremely uncommon in the ampulla of Vater and only 32 previous cases have been described in the literature [2].

Little is known about this tumor's natural history and prognosis.

Histologically, the origin of signet-ring cells remains unknown, but the following hypotheses have been proposed by various investigators. One is that SRCC arises from ectopic gastric mucosa found in the duodenum [7] [8]. Another theory is that SRCC arises from areas of gastric-type metaplastic epithelia. These metaplastic changes are considered to be a protective response to elevated acidity and have usually been seen at the duodenal bulb in peptic ulcer patients [9]. In this theory, signet-ring cell carcinoma originates from periampullary duodenal heterotopias of an ulcerative etiology and expands to the ampulla of Vater.

In our case, there was no ectopic gastric mucosa found in the peritumoral mucosa, and the patient had no history of peptic ulcer disease.

33 cases of SRCC of Vater's ampulla that have been reported in the literature.

Metesh [2] presented the report of the 30 preceding cases, included 16 males and 9 females aged between 32 and 83 years of age. One patient presented with T4 disease, ten patients with T3 disease and eight with T2 disease.

Akatsu [5] has summarized the previous 14 cases (eight men and six women) and concluded that the median age at diagnosis was 57 years (range, 32 - 83 years), approximately 15 years older than SRCC of the stomach, but similar to the median age for SRCC of the large bowel.

Hara [10] presented the report of seven patients. The mean age was 60.3 years (range: 25 - 72 years). Jaundice was the most common symptom (5 out of 7 patients); the macroscopic appearance was superficial-protruding (4 cases), ulcerative (2 cases) or diffuse infiltrative (1 case).

For the diagnosis of SRCC, helical computed tomography (CT) showes a dilated CBD (common bile duct) without a mass lesion in the ampulla of Vater in some cases [11]-[13].

Contrast-enhanced ultrasound (CEUS) has gained increasing interest in recent years and may provide an effective means of diagnosis of ampullary carcinomas. The lesion may be displayed much clearer than by conventional gray-scale ultrasound and it can also offer a good method in the discrimination of ampullary carcinoma from non-malignant lesions [14].

The majority of patients in previous cases of ampullary SRCC underwent pancreaticoduodenectomy, occasionally with extended lymphadenectomy and/or partial gastrectomy. This radical approach facilitates lymph node dissection in advanced disease, but a pylorus-preserving technique, which has been utilised in three previous cases of ampullary SRCC [10] [15] [16], may be more applicable in early disease, where curability is balanced by a more moderate resection.

In our case, the preoperative diagnosis was an advanced tumor with invasion of the duodenum wall, so a pancreaticoduodenectomy and extended lymphadenectomy were performed.

Our patient had the typical characteristics of other cases in terms of age, jaundice, macroscopic appearance. Abdominal computed tomography showed a tumor in the ampulla of Vater with invasion of D3 and a dilatation 
of the extra hepatic bile duct and the same treatment approach, and TNM classification.

Adjuvant chemotherapy may be appropriate in the treatment of ampullary SRCC associated with loco- regional metastasis. However, its role in node-negative and distant metastatic disease remains as yet undetermined and, from the case reports evaluated, consensus regarding the optimum chemotherapeutic regimen is lacking [2].

SRCC localized in other digestive organs have a poor prognosis.

The experience from previously reported cases of carcinoma of the ampulla of Vater suggests a good prognosis, provided there is no metastasis at the time of surgery [2]. But lymph node involvement, is a determinant prognostic factor in cancer of the ampulla of Vater [10].

Duodenopancreatectomy with pylorus preservation is the treatment of choice in ampullar cancers [10]. Adjuvant therapy has not showed survival benefit in patients without lymph node infiltration [2].

\section{Conclusions}

We report a very rare case of SRCC of the ampullary of vater with invasion of the duodenum without lymphom node infiltration or distant metastatic disease.

Pancreaticoduodenectomy is the treatment of choice for localized disease.

Although several cases have been reported, the detailed clinicopathological features and prognosis are not clear. More case reports are needed to establish the role of adjuvant chemotherapy in this tumor.

\section{References}

[1] Kim, D.I., Park, S.W., et al. (2010) A case of signet-ring cell carcinoma of the ampulla of Vater. Korean Journal of Gastrointestinal Endoscopy, 41, 251-254. (in Korean)

[2] Acharya, M.N., Panagiotopoulos, N., et al. (2013) Poorly-Differentiated Signet-Ring Cell Carcinoma of the Ampulla of Vater: Report of a Rare Malignancy. Journal of the Pancreas, 14, 190-194.

[3] Ishibashi, Y., Ito, Y., et al. (2009) Signet Ring Cell Carcinoma of the Ampulla of Vater. A Case Report. Journal of the Pancreas, 10, 690-693.

[4] Li, L., Chen, Q.H., et al. (2004) Signet-Ring Cell Carcinoma of the Ampulla of Vater. Annals of Clinical \& Laboratory Science, 34, 471-475.

[5] Akatsu, T., Aiura, K., et al. (2007) Signet-Ring Cell Carcinoma of the Ampulla of Vater: Report of a Case. Surgery Today, 37, 1110-1114. http://dx.doi.org/10.1007/s00595-007-3534-4

[6] Yokota, T., Kunii, Y., et al. (1998) Signet Ring Cell Carcinoma of the Stomach: A Clinicopathological Comparison with the Other Histological Types. The Tohoku Journal of Experimental Medicine, 186, 121-130. http://dx.doi.org/10.1620/tjem.186.121

[7] Gardner, H.A., Matthews, J., et al. (1990) A Signet-Ring Cell Carcinoma of the Ampulla of Vater. Archives of Pathology \& Laboratory Medicine, 114, 1071-1072.

[8] Ramia, J.M., Mansilla, A., et al. (2004) Signet Ring Cell Carcinoma of the Vater's Ampulla. Journal of the Pancreas, 5, 495-497.

[9] Hoedemaeker, P.J. (1970) Heterotopic Gastric Mucosa in the Duodenum. Digestion, 3, 165-173. http://dx.doi.org/10.1159/000197027

[10] Hara, T., Kawashima, H., et al. (2002) Signet-Ring Cellcarcinoma of the Ampulla of Vater: A Case Report. Hepatogastroenterology, 49, 561-563.

[11] Bloomston, M., Walker, M., et al. (2006) Radical Resection in Signet ring Carcinoma of the Ampulla of Vater: Report of an 11-Year Survivor. The American Surgeon, 72, 193-195.

[12] Li, L., Chen, Q.H., et al. (2004) Signet-Ring Cell Carcinoma of the Ampulla of Vater. Annals of Clinical \& Laboratory Science, 34, 471-475.

[13] Eriguchi, N., Aoyagi, S., et al. (2003) Signet-Ring Cell Carcinoma of the Ampulla of Vater: Report of a Case. Surgery Today, 33, 467-469. http://dx.doi.org/10.1007/s10595-002-2509-9

[14] Gao, J.-M., Tang, S.-S., et al. (2009) Signet-Ring Cell Carcinoma of Ampulla of Vater: Contrast-Enhanced Ultrasound Findings. World Journal of Gastroenterology, 15, 888-891. http://dx.doi.org/10.3748/wjg.15.888

[15] Paplomata, E. and Wilfong, L. (2011) Signet Ring Cell Carcinoma of the Ampulla of Vater with Leptomeningeal Metastases: A Case Report. Journal of Clinical Oncology, 29, e627-e629. http://dx.doi.org/10.1200/JCO.2011.35.2385

[16] Valeri, S., Caricato, M., et al. (2005) Signet-Ring Cell Carcinoma of the Vater's Ampulla: Report of a Clinical Case. I Supplementi di Tumori, 4, S61. 